\title{
Correlation of Internal Organ Weights with Body Weight and Body Height in Normal Adult Zambians: A Case Study of Ndola Teaching Hospital
}

\author{
Lumamba Mubbunu $\mathbb{D}^{\mathrm{D}},{ }^{1}$ Kasonde Bowa, ${ }^{1}$ Volodymyer Petrenko, ${ }^{2}$ and Moono Silitongo $\mathbb{D}^{1}$ \\ ${ }^{1}$ Department of Basic Science, Michael Chilufya Sata School of Medicine, Copperbelt University, P.O. Box 71191, Ndola, Zambia \\ ${ }^{2}$ Department of Pathology, Ndola Teaching Hospital, Postal Agency, Ndola, Zambia \\ Correspondence should be addressed to Lumamba Mubbunu; lumamba84@outlook.com
}

Received 5 October 2017; Accepted 13 March 2018; Published 18 April 2018

Academic Editor: Fred Sinowatz

Copyright (C) 2018 Lumamba Mubbunu et al. This is an open access article distributed under the Creative Commons Attribution License, which permits unrestricted use, distribution, and reproduction in any medium, provided the original work is properly cited.

\begin{abstract}
The objective of the research was to study the correlation of internal organ weights with body weight and length in normal adult Zambians. The study involved 114 (83 males and 31 females) forensic autopsies from Ndola Teaching Hospital done over a period of 12 months. The cases included autopsies of unnatural deaths including road traffic accidents and homicide. Cases where information about age and origin of the person was not available were left out of the study. The age of the decedents ranged from 16 to 85 years. The data was analyzed by Pearson correlation coefficient to determine correlation. $P$ values less than 0.05 were considered to be statistically significant. It was observed that the heart, liver, left kidney, right kidney, brain, and left lung were positively correlated to body weight, while only the brain and the left lung were positively correlated to the height in the male population. In the female population, the heart, liver, right kidney, brain, and right lung were positively correlated to the weight of the body, while only the right kidney was positively correlated to the height of the body.
\end{abstract}

\section{Introduction}

The weight of internal organs is important in forensic medicine and pathology, because the weight of internal organs is useful in determining whether the organ is normal or pathological. Many diseases have been shown to change the weight of internal organs $[1,2]$. The change in the weight of an internal organ can be used in interpreting the opinion regarding the cause of death during an autopsy. Changes in the weight of an internal organ may be the only evidence to show that an organ is not normal. For example, the elevated weight of the heart may be the only evidence to myocardial hypertrophy that is often macroscopically and microscopically difficult to recognize [3]. In a similar vein, in a study by Greaves in 2000 [4], he reported that changes in kidney weight may also reflect renal toxicity, tubular hypertrophy, or chronic progressive nephropathy. In forensic pathology as well as in clinical medicine any deviation from the normal weight of an internal organ would be indicative of a pathology to that organ or a compensatory mechanism in response to applied stress to an organ. For example, if there is increased pulmonary resistance, the right ventricle of the heart may enlarge in response to the increase in the pressure required to pump blood through the pulmonary circulation [5]. The increase in the weight of an internal organ can only be determined if there is a reference weight, in this case the recorded weight of that internal organ to which the weight of an internal organ can be compared to. Since the determination of the normal weight of an internal organ is based on comparison with the reference data, the reference data should as much as possible be representative and be as accurate as can be to show that the reference weight shows the normal value [6]. The weight of internal organs can be a good diagnostic criteria for interpreting autopsy information if the weights of internal organs are compared to the appropriate reference weights $[7,8]$. This means that normality for the weight of internal organs in a given population should be accurately defined. One of the ways to define this data is to 
generate reference tables for that population, meaning the average weight to be used as reference information should be generated from the people of that population. Another method that can be used to normalize the information is correlation of internal organ weights to body length and body weight. As it stands Zambian pathologists use references from American or European textbooks. The problem with these sources of information is that they may not be suitable for the Zambian population when interpreting postmortem cases. This could lead to inaccurate interpretation of postmortem cases. Human internal organ weights not only are determined by race, age, or gender but are also anticipated to be dependent on environmental and social economic conditions which may be quite different in various parts of the world. Hence, the weights of organs reported from other countries may not be the same as that for Zambian population. The current work was undertaken to study the average weight of Zambian population and correlate the weight of internal organs with body weight and height.

\section{Materials and Methods}

The study was undertaken at Ndola Teaching Hospital mortuary. The organs were weighed from selected bodies that satisfied the criteria for inclusion in the study. The bodies were selected from postmortem cases brought to the pathologists for forensic investigations for a period of 12 months. During this period, 114 cases were sampled, and all the autopsies that were used in the study were done by the same pathologist and anatomist. In the study, subjects who died due to natural causes were not included; this was because the organs in patients succumbing to a variety of morbid anatomical lesions or disease process were considered to be pathological. The assumption was that the ideal subjects for establishing the weight of internal organs would for those dying from accidental and violent deaths [9]. The assumption is that decedents who die accidentally are healthy. For the purposes of this study, normal organ was defined as an organ from a person who did not have any evidence of any type of disease or infection that would damage that organ: the gross appearance of the organs had to be without any evidence of any type of damage and or pathology.

2.1. Inclusion Criteria. Cases of accidents and homicide, where there was no evidence of gross pathology or trauma to the internal organs of interest were selected for inclusion. Postmortem examination was carried out within 24 hours and petrification had not occurred on the body and organs. If the body stayed too long more than 48 hours in the fridges at the mortuary that case was not included. The decedents were all natives of Zambia. The autopsy case was a forensic or medical legal autopsy.

2.2. Exclusion Criteria. Cases not satisfying the above criteria were excluded.

2.3. Ethical Approval. Ethical clearance was granted by Tropical Diseases Research Center ethical review committee: IRB registration number: 00002911. FWA number is 00003729. The study number for this study is TDRC/ERC/01/07/2014.

\section{Data Collection}

The height was measured from head to heel using a height measure in centimeters. The body was weighed naked [6, 7]. Using a scale $0.0 \mathrm{Kg}$ to $300 \mathrm{~kg}$ with accuracy of $\pm 100 \mathrm{~g}$, the scale was calibrated by the Zambia weight and measure agency and $0.5,1.0$, and $5.0 \mathrm{Kg}$ control weights were used to calibrate the scale every time before it was used. The internal organs were weighed using a calibrated electronic balance $0.0 \mathrm{~g}$ to $5000 \mathrm{~g}$ with accuracy of $\pm 0.1 \mathrm{~g}$. The collected data was analyzed using IBM-SPSS program version 23 . They were divided into gender: male and female. Person's correlation coefficient was used to analyze the relationships between body weight and body length of the internal organs at $P<$ 0.05 .

Results. The subjects of the study were divided into groups comprised of males and females.

\section{Discussion}

The sample population for this study was made up of people who had died in road traffic accidents and homicide cases that were brought to Ndola Teaching Hospital for autopsy. 114 cases were selected for the study: 31 females and 83 males. The age group for the females was $18-85$ years with the average age of $39.9 \pm 15.2$ years, while that of the males was $16-85$ years with an average of $38.1 \pm 16.0$ years (see Table 1 ). The weight and height of the decedents were also measured, and the average weight and height for the female population were $57.5 \pm 11.2 \mathrm{Kg}$ and $163.4 \pm 6.7 \mathrm{~cm}$, respectively, while those of the male population were $58.5 \pm 11.2 \mathrm{Kg}$ and $169.2 \pm 7.84 \mathrm{~cm}$ (See Table 1). $90 \%$ of the samples decedents deaths were road traffic accidents and $10 \%$ suspected murder cases.

4.1. Heart. The weight of the heart was $279.2 \pm 44.9 \mathrm{~g}$ in males and $268.4 \pm 64.2 \mathrm{~g}$ in the female population representing $0.48 \%$ and $0.47 \%$ of body weight, respectively (Tables 1 and 3). Body weight percent of the heart was different when compared to other authors $[10,11]$. The weight of the heart was positively correlated with body weight in both males and females at $P<0.05$ (see Table 2). The weight of the heart was not correlated to the height of the body in both males and females (see Table 2). Other researchers [7] found that the weight of the heart was positively correlated to the weight in both males and females, while the weight of the heart was only positively correlated to the height of the body in males and not in female decedents in Thai population which is different from the findings of this study. In the same vein, Hanzlick and Rydzewski [12] found that the weight of the heart in males is correlated to body weight and length, whereas the weight of the heart in females is correlated only to body weight but not correlated to body height.

4.2. Spleen. The weight of the spleen was found to be 169.9 $\pm 107.2 \mathrm{~g}$ in males and $161.7 \pm 93.4 \mathrm{~g}$ in females (Table 1$). \mathrm{In}$ 
TABLE 1: Mean, standard deviation, maximum of body weight, body height, age, and weight of internal organs.

\begin{tabular}{|c|c|c|c|c|}
\hline & \multicolumn{2}{|c|}{ Male $N=83$} & \multicolumn{2}{|c|}{ Female $N=31$} \\
\hline & Min-max & Mean and SD & Min-max & Mean and SD \\
\hline Age & $16-85$ years & $38.1 \pm 16.0$ years & $18-85$ years & $39.9 \pm 15.2$ years \\
\hline Weight & $33 \mathrm{Kg}-87 \mathrm{Kg}$ & $58.5 \pm 11.20 \mathrm{Kg}$ & $36-77 \mathrm{Kg}$ & $57.5 \pm 11.2 \mathrm{Kg}$ \\
\hline Height & $149-187 \mathrm{~cm}$ & $169.0 \pm 7.84 \mathrm{~cm}$ & $151-176 \mathrm{~cm}$ & $163.4 \pm 6.7 \mathrm{~cm}$ \\
\hline Heart & $169-379 \mathrm{~g}$ & $279.2 \pm 44.9 \mathrm{~g}$ & $180-451 \mathrm{~g}$ & $268.4 \pm 64.2 \mathrm{~g}$ \\
\hline Liver & 649-1894 g & $1285.3 \pm 270.1 \mathrm{~g}$ & $828-2154 \mathrm{~g}$ & $1367.9 \pm 357.2 \mathrm{~g}$ \\
\hline Spleen & $44-468 \mathrm{~g}$ & $169.9 \pm 107.2 \mathrm{~g}$ & $28-515 \mathrm{~g}$ & $161.7 \pm 93.4 \mathrm{~g}$ \\
\hline Right kidney & $70-175 \mathrm{~g}$ & $110.0 \pm 22.8 \mathrm{~g}$ & $61-152 \mathrm{~g}$ & $101.2 \pm 20.3 \mathrm{~g}$ \\
\hline Left kidney & $71-193 \mathrm{~g}$ & $117.9 \pm 27.4 \mathrm{~g}$ & $75-180 \mathrm{~g}$ & $108.3 \pm 23.0 \mathrm{~g}$ \\
\hline Brain & $1054-1630$ & $1335.0 \mathrm{~g} \pm 125.5$ & $1064-1400 \mathrm{~g}$ & $1228.3 \pm 76.4 \mathrm{~g}$ \\
\hline Left lung & $144-922$ & $442.0 \mathrm{~g} \pm 152.3 \mathrm{~g}$ & $216-691 \mathrm{~g}$ & $365.7 \pm 119.8 \mathrm{~g}$ \\
\hline Right lung & $230-1053$ & $504.6 \pm 174.6 \mathrm{~g}$ & $235-795 \mathrm{~g}$ & $405.0 \pm 116.0 \mathrm{~g}$ \\
\hline
\end{tabular}

TABLE 2: Correlation between internal organ weight and body weight and height.

\begin{tabular}{|c|c|c|c|c|c|c|c|c|}
\hline \multirow{3}{*}{$\begin{array}{l}\text { Organ } \\
\text { Heart }\end{array}$} & \multicolumn{4}{|c|}{ Male $N=83$} & \multicolumn{4}{|c|}{ Female $N=31$} \\
\hline & \multicolumn{2}{|c|}{ Body weight } & \multicolumn{2}{|c|}{ Body height } & \multicolumn{2}{|c|}{ Body weight } & \multicolumn{2}{|c|}{ Body height } \\
\hline & $r=0.575$ & $P<0.001$ & $r=0.211$ & $P=0.056$ & $r=0.353$ & $P=0.047$ & $r=0.349$ & $P=0.050$ \\
\hline Liver & $r=0.310$ & $P=0.004$ & $r=0.045$ & $P=0.685$ & $r=0.554$ & $P<0.001$ & $r=0.291$ & $P=0.106$ \\
\hline Spleen & $r=0.001$ & $P=0.996$ & $r=-0.102$ & $P=0.361$ & $r=0.198$ & $P=0.227$ & $r=0.295$ & $P=0.102$ \\
\hline Left kidney & $r=0.331$ & $P=0.002$ & $r=0.018$ & $P=0.875$ & $r=0.256$ & $P=0.157$ & $r=0.236$ & $P=0.193$ \\
\hline Right kidney & $r=0.275$ & $P=0.013$ & $r=-0.013$ & $P=0.906$ & $r=0.400$ & $P=0.023$ & $r=0.368$ & $P=0.038$ \\
\hline Brain & $r=0.490$ & $P<0.001$ & $r=0.401$ & $P<0.001$ & $r=0.396$ & $P=0.025$ & $r=-0.049$ & $P=0.788$ \\
\hline Left lung & $r=0.259$ & $P=0.018$ & $r=0.237$ & $P=0.031$ & $r=0.242$ & $P=0.182$ & $r=0.128$ & $P=0.483$ \\
\hline Right lung & $r=0.130$ & $P=0.168$ & $r=0.196$ & $P=0.076$ & $r=0.394$ & $P=0.026$ & $r=0.096$ & $P=0.600$ \\
\hline
\end{tabular}

The percent body weight was also calculated for the weight of internal organs. This was done to get an estimate of percent body weight for each organ that was studied.

this study, the weight of the spleen was not correlated to the weight and height of the spleen at $P<0.05$ (Table 2). Other authors have indicated that the spleen is positively correlated to body weight in males [7]. Similarly, Mathuramon et al. [6] found that the weight of the spleen is positively correlated to body weight and height in males and not in females. It is postulated that this may have been because the population that was studied is in a malaria endemic country and the size of the spleen could have been due to parasitic infections. Parasitic infections have been observed to cause increase to the weight of the spleen [13]. The weight of the spleen was $0.28 \%$ in males and $0.28 \%$ in females (Table 3 ). The figures in this study are higher than the findings of Tanna et al. [14] in which they found percent body weight of the spleen at $0.15-0.25 \%$ in males and $0.18-0.24 \%$ in females.

4.3. Liver. The weight of the liver was found to be 1285.3 $\pm 270.1 \mathrm{~g}$ and that of females $1367.9 \pm 357.2 \mathrm{~g}$ (Table 1 ). The weight of the liver was positively correlated to body weight in both males and females at $P<0.05$ (Table 2). The finding is similar to the findings in the Thai population [6]; however the weight of the liver did not correlate with the height of the decedents in the study (see Table 2). The percent body weight of the liver in males was $2.2 \%$ while it was $2.4 \%$ in female decedents (see Table 3). The findings are different from those of Standring [10] and Tanna et al. [14].

4.4. Lungs. The weight of the lungs was found to be 442.0 $\pm 152.3 \mathrm{~g}$ left lung and $504.6 \pm 174.6 \mathrm{~g}$ right lung in the male population while in the female population the weight of the left lung was $365.7 \pm 119.8$ and the right lung $405.0 \pm 116.0 \mathrm{~g}$ (Table 1). The percent body weight of the lungs in males was $0.76 \%$ for the left lung and $0.86 \%$ for the right lung. In the female decedents, the left lung was $0.64 \%$ and the right lung was $0.70 \%$ of body weight (Table 3 ). The findings in this study are different from other researchers [14]. The weight of the left lung was positively correlated to the weight and height of the body in males; however there was no correlation with either body weight or body height in the female decedents at $P<0.05$ (Table 2 ). The weight of the right lung was positively correlated to the weight of the body in females while there was no correlation with the height of the decedents. In the male decedents, there was no correlation with the weight of the right lung with body weight and body height. Other studies which have shown that there is a positive correlation between body weights in males had the weight of the lungs combined to give total lung weight $[6,7,15]$. In this work, the left lung and right lung were analyzed independent of each other. 
TABLE 3: Percent body weight of the organs in both male and female population.

\begin{tabular}{|c|c|c|c|c|c|}
\hline Organ & Weight & $\begin{array}{c}\text { Male } \% \\
\text { Body weight }\end{array}$ & Organ & Weight & $\begin{array}{c}\text { Female \% } \\
\text { Body weight }\end{array}$ \\
\hline Heart & $279.2 \pm 44.9 \mathrm{~g}$ & $0.48 \%$ & Heart & $268.4 \pm 64.2 \mathrm{~g}$ & $0.47 \%$ \\
\hline Liver & $1285.3 \pm 270.1 \mathrm{~g}$ & $2.20 \%$ & Liver & $1367.9 \pm 357.2 \mathrm{~g}$ & $2.38 \%$ \\
\hline Spleen & $169.9 \pm 107.2 \mathrm{~g}$ & $0.29 \%$ & Spleen & $161.7 \pm 93.4 \mathrm{~g}$ & $0.28 \%$ \\
\hline Left kidney & $117.9 \pm 27.4 \mathrm{~g}$ & $0.20 \%$ & Left kidney & $108.3 \pm 23.0 \mathrm{~g}$ & $0.19 \%$ \\
\hline Right kidney & $110.0 \pm 22.8 \mathrm{~g}$ & $0.19 \%$ & Right kidney & $101.2 \pm 20.3 \mathrm{~g}$ & $0.18 \%$ \\
\hline Brain & $1335.0 \mathrm{~g} \pm 125.5$ & $2.28 \%$ & Brain & $1228.3 \pm 76.4 \mathrm{~g}$ & $2.13 \%$ \\
\hline Left lung & $442.0 \mathrm{~g} \pm 152.3 \mathrm{~g}$ & $0.76 \%$ & Left lung & $365.7 \pm 119.8 \mathrm{~g}$ & $0.64 \%$ \\
\hline Right lung & $504.6 \pm 174.6 \mathrm{~g}$ & $0.86 \%$ & Right lung & $405.0 \pm 116.0 \mathrm{~g}$ & $0.70 \%$ \\
\hline Body weight & $58.5 \pm 11.2 \mathrm{Kg}$ & & Body weight & $57.47 \pm 11.2 \mathrm{Kg}$ & \\
\hline
\end{tabular}

4.5. Kidneys. The weight of the kidneys was found to be 110.0 $\pm 22.8 \mathrm{~g}$ right kidney and $117.9 \pm 27.4$ left kidney in the males and $101.2 \pm 20.3 \mathrm{~g}$ right kidney and $108.3 \pm 23.0 \mathrm{~g} \mathrm{left}$ kidney in females (Table 1). The weight of the left kidney and right kidney represented $0.20 \%$ and $0.19 \%$, respectively, in the male decedents (see Table 3 ). The left kidney represented $0.19 \%$ and the right kidney $0.18 \%$ in females (Table 1$)$. The findings are similar to findings by Tanna et al. [14] for the percentage body weight of the kidneys. Both the left and right kidney were positively correlated to body weight at $P<0.05$ (Table 2), while there was no correlation for both the left and right kidney with body height in the male decedents. In the female decedents, the right kidney was positively correlated with body weight and height while the left kidney was not. This is different from the findings of Prakash et al. 2013. Other authors have shown that the combined weight of the kidneys is positively correlated to body weight and height in both male and female decedents [6].

4.6. Brain. The weight of the brain was $1335.0 \pm 25.5 \mathrm{~g}$ in the male decedents and $1228.3 \pm 76.4 \mathrm{~g}$ in females representing $2.28 \%$ and $2.31 \%$ of body weight, respectively, in male and female decedents (see Tables 1 and 3 ). The average weight of the brain in this study was positively correlated with the weight and height of the male decedents, while, in female decedents, the weight of the brain was positively correlated with the weight of the body but not the height of the body (Table 2). The percentage body weight of the liver in this population was greater than that of the Bhavnagar region of India [14]. A study by Mathuramon et al. [6] shows that the weight of the brain is not positively correlated to the height of the body in the decedents in both males and females; this is different from the findings of this study. Prakash et al. [15] however found that the weight of the brain was positively correlated to the weight of the body in female and not in male decedents.

4.7. Strengths of the Study. It should be noted that this study differs from other studies because the data was collected prospectively. By so doing the researchers were able to see the subjects which gave the researchers more information on the rejection and inclusion criteria, other studies that have used retrospective records to analyze the correlation of internal organ weights with body weight and height relied on information collected by others and may include organ weights from subjects that maybe otherwise would have been rejected. The same pathologist and anatomist collected the data which means that the method of cutting and weighing the organs was consistent thereby reducing errors which would arise from having many people involved in collection of data.

4.8. Limitation and Weaknesses of the Study. The study had the following limitations: there was no information about the kind of life the subjects in the study lived and the medical condition of the subject at the time of death was not known. The answers about the medical condition of the subjects would have helped a great deal in refining the weight of internal organs. Histological studies could have also helped in removing weights of internal organs that may have looked normal or were of gross appearance and yet pathological. It was not easy to get a large sample size, especially with the female sample which were 32 in number, in which case the interpretation of the data for the female population should be done with a lot of caution. The study may not be suitable in interpreting autopsy of people from other provinces within Zambia.

\section{Conclusion}

In this study, it was observed that the heart, liver, left kidney, right kidney, brain, and left lung were positively correlated to body weight, while only the brain and the left lung were positively correlated to the height in the male population. In the female population, the heart, liver, right kidney, brain, and right lung were positively correlated to the weight of the body, while only the right kidney was positively correlated to the height of the body. Further work is required with a larger sample population to ascertain the true relationships of the weight of internal organ with body weight and height.

\section{Recommendations}

Further work will need to be done in this area with a large population of at least 2000 subjects to improve the statistical validity of the arguments. All regions of Zambia will have to be covered not just one center like Ndola central hospital in 
this case. Multiple centers and increased period of study may increase the sample size.

\section{Conflicts of Interest}

The authors declare that they have no conflicts of interest.

\section{References}

[1] V. Kumar, A. Abbas. Fausto. N, and C. Robbin, Pathological Basis of Disease, Elsevier Saunders, Philadelphia, Pennsylvania, 7th edition, 2005.

[2] W. U. Spritz, Fisher'S Medicolegal Investigation of Death, Thomas Publishers, Springfield, IL, USA, 3rd edition, 1993.

[3] K. Thiedemann, Left ventricular hypertrophy in cardiovascular and musculoskeletal systems, W. Jones and R. D. Hunt, Eds., Springer-Verlag, 1991.

[4] P. Greaves, Histopathology of Preclinical Toxicity Studies: Interpretation And Relevance in Drug Safety Evaluation, Elsevier Science Amsterdam, 2nd edition, 2000.

[5] L. Zhao, A. Sebkhi, D. J. R. Nunez et al., "Right ventricular hypertrophy secondary to pulmonary hypertension is linked to rat chromosome 17: Evaluation of cardiac ryanodine Ryr2 receptor as a candidate," Circulation, vol. 103, no. 3, pp. 442-447, 2001.

[6] P. Mathuramon, T. Chirachariyavej, A. V. M. V. Peonim, and M. Rochanawutanon, "Correlation of internal organ weight with body weight and length in normal thai adults," Journal of the Medical Association of Thailand, vol. 92, no. 2, pp. 250-258, 2009.

[7] T. Chirachariyavej, K. Ouyswat, S. Sanggarnjanavanich, M. Tiensuwan, V. Peonim, and V. Sirikulchayanonta, "Normal internal organ weight of Thai adults correlated to body length and body weight," Journal of the Medical Association of Thailand, vol. 89, no. 10, pp. 1702-1712, 2006.

[8] F. Young, H. Luecke, B. Pearce, T. Lee, and H. Ahn, "Human Organ/Tissue growth algorithms that include obese individuals and black/white population organ weight similarities from autopsy data," Journal of Toxicology and Environmental Health, vol. 72, pp. 527-540, 2009.

[9] R. Pearl and L. Bacon, "Biometrical studies in pathology," in John Hopkins hospital Rep, pp. 21-351, 21, 351, 1924.

[10] S. Standring, Grays' Anatomy, Anatomical Basis of Clinical Practice, UK, Churchill Livingstone, Elsevier, 41st edition, 2016.

[11] V. Kumar, A. Abbas. Fausto. N, and C. Aster, Robins and Contran: Pathological basis of disease, Elsevier Saunders USA, Philadelphia, Pennsylvania, 8th edition, 2010.

[12] R. Hanzlick and D. Rydzewski, "Heart weights of white men 20 to 39 years of age. An analysis of 218 autopsy cases," The American Journal of Forensic Medicine and Pathology, vol. 11, no. 3, pp. 202-204, 1990.

[13] M. A. Dunn, Parasitic diseases in Schiff's disease of the liver, E. R. Schiff, W. C. Maddrey, and M. F. Sowell, Eds., Oxford Uk, 2011.

[14] J. Tanna, P. Patel, and D. Kalele, "Originl research paper: relation between organ weights and body weight in adukt population of Bhavnagar region- a post-mortem study," Journal of Indian Academy of Forensic Medicine, vol. 33, 2011.

[15] C. Prakash, D. Deopa, and H. Thakkar, "Study of Internal Organ Weight and its Correlation to Body Wight in Kumaon Region. Of Uttarakhand," Journal of Indian Academy of Forensic Medicine, vol. 35, no. 1, 2013. 


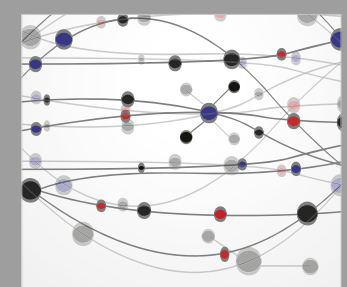

The Scientific World Journal
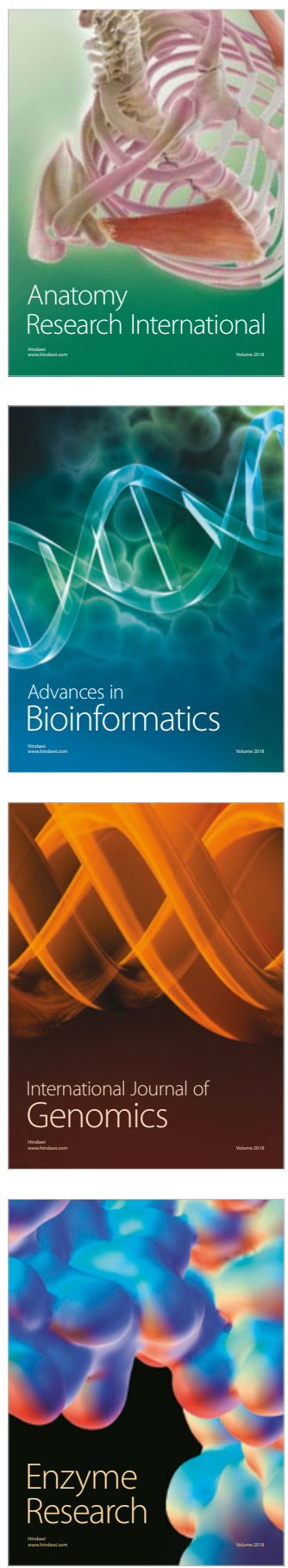
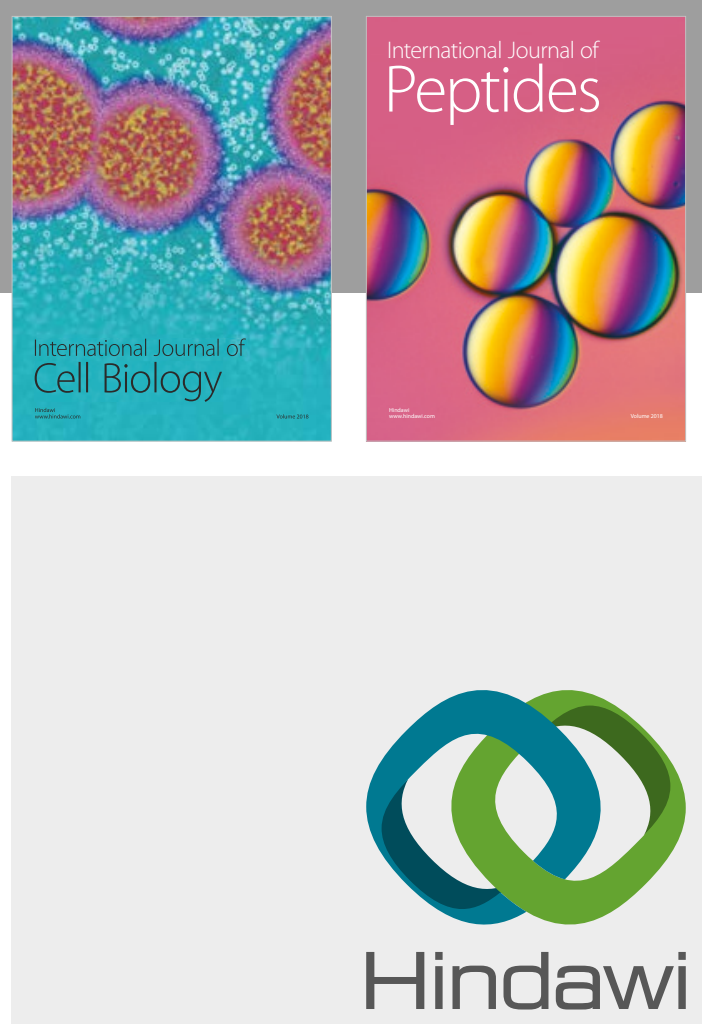

Submit your manuscripts at

www.hindawi.com
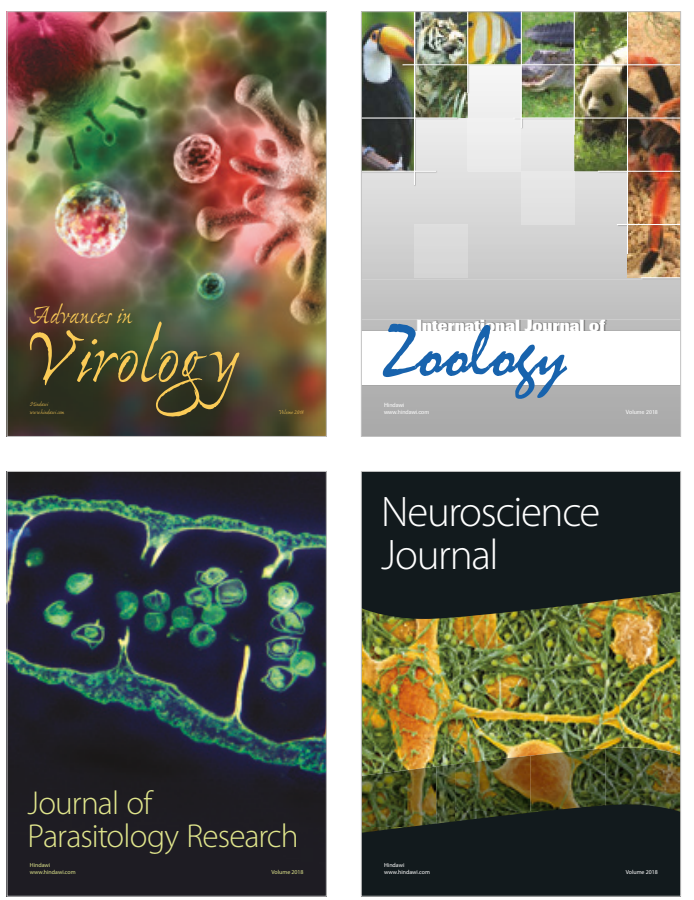
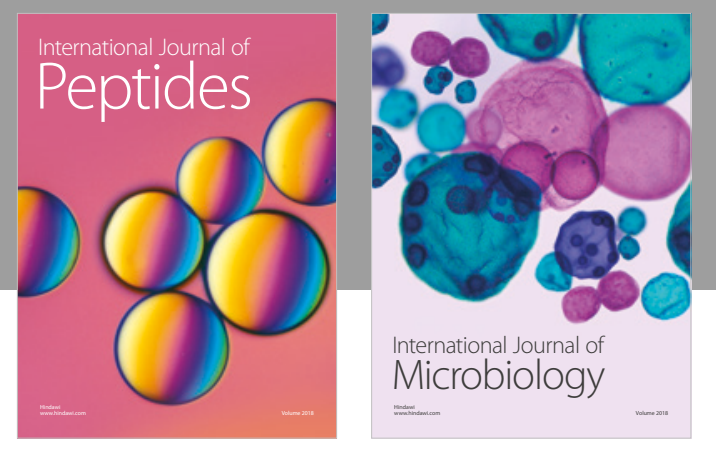

nternational Journal of Microbiology
Journal of
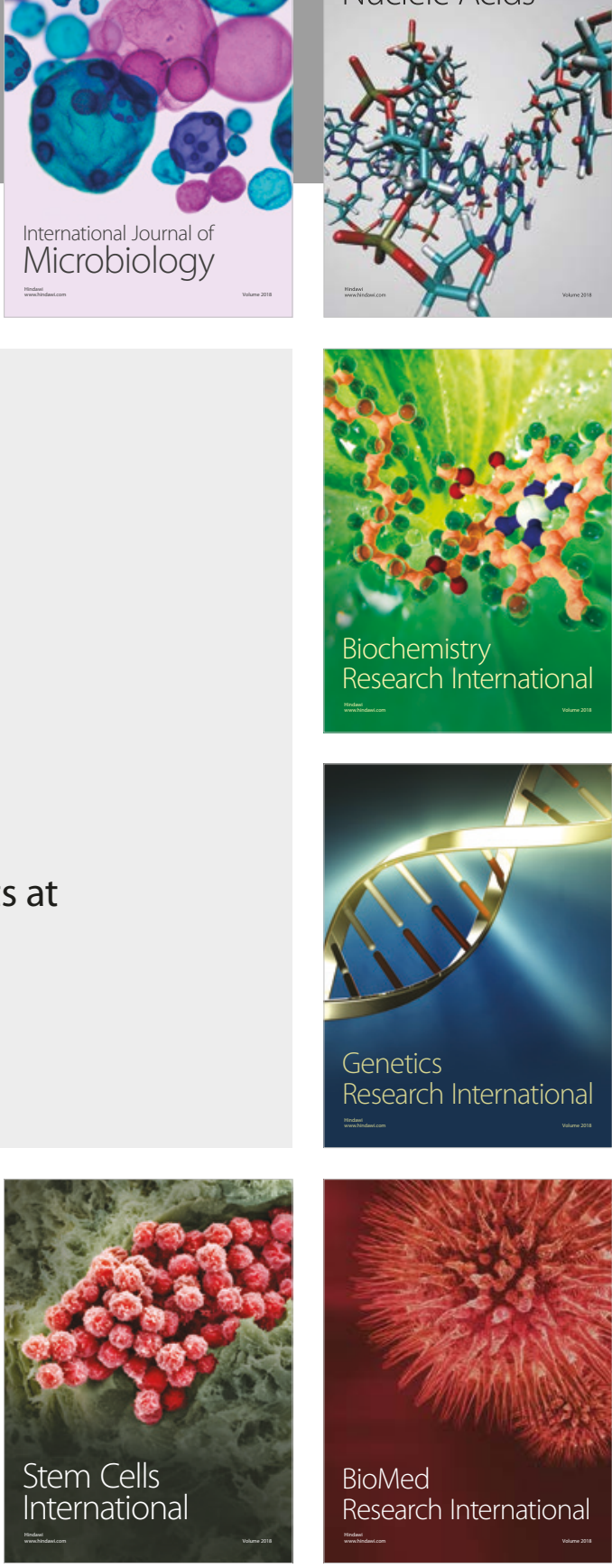
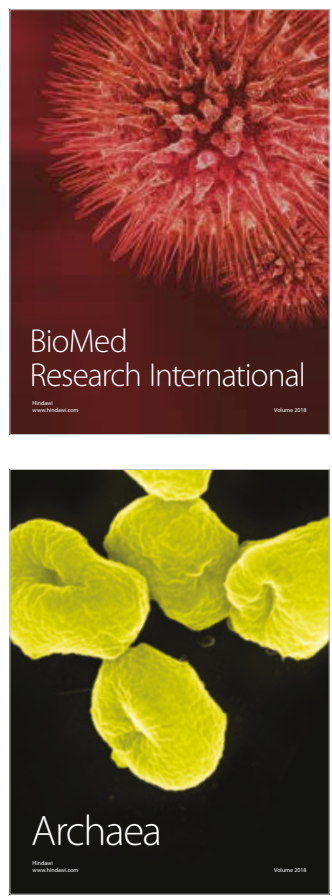